\title{
Geopolymer Concrete: an Emerging Green Material for Modern Construction
}

\author{
Ritupanna Panda, Sagarika Panda, A. M. Mohant
}

\begin{abstract}
Nowadays the environmental health is considered to be the most important topic for concern. The emission of $\mathrm{CO}_{2}$ and other harmful gases to the atmosphere become a serious problem and the root cause of environmental alteration. In other ways, the production of cement is reducing continuously due to the unavailability of resources and a large amount of carbon footprint. To overcome all these problems the low $\mathrm{CO}_{2}$ emitting and alumina silicate rich sources are used as binders instead of ordinary cement. The paper reviews all the recent and experimental works done by the researchers in order to study the physical and mechanical properties of Geopolymer Concrete with different mixtures of binders and additives introduced for increasing the strength and durability. The use of different industrial by-products in concrete development is encouraged and the workability, effects of temperature variation, use of admixture, fibers and effects of water- binder ratio for the Geopolymer Concrete are examined. Reviews indicate that the compressive strength of the Geopolymer Concrete with additional hooked end steel fibers are more than that of controlled Geopolymer Concrete mix.
\end{abstract}

Keywords: Geopolymer Concrete (GC); Compressive strength; Splitting Tensile strength; Durability.

\section{INTRODUCTION}

The process of reactions takes place between monomer molecules and reacting chemical to form three-dimensional chains is commonly stated as polymerization. Geopolymers are the inorganic materials that are formed when a base material rich in alumina and silica reacts with a very strong alkaline solution, termed as geo-polymerization. Ergo geopolymer concrete, in simple terms, can be expressed as an alternate sustainable material to ordinary concrete material. The term 'Geopolymer Concrete' was first termed and assayed by Davidovits in the year 1974.

Recently, in a national conference in IMMT, Bhubaneswar it is discussed that the limestone content in the earth is reducing day-by-day. Thence the scarcity of limestone will affect the manufacturing of the cement being the raw material brutally.

\section{Revised Manuscript Received on February 05, 2020.}

* Correspondence Author

Ritu panna Panda*, Research Scholar, Civil Engineering Department, Centurion University of Technology And Management, Bhubaneswar, Odisha, India. Email : sagarikapanda1988@gmail.com

Sagarika Panda, Assistant Professor, Civil Engineering Department, Centurion University of Technology and Management, Bhubaneswar, Odisha, India. Email : sagarikapanda1988@gmail.com

A. M. Mohanty Professor, Mechanical Engineering Department, Centurion University of Technology and Management, Bhubaneswar, Odisha, India. Email : provc@cutm.ac.in

(C) The Authors. Published by Blue Eyes Intelligence Engineering and Sciences Publication (BEIESP). This is an open access article under the CC BY-NC-ND license (http://creativecommons.org/licenses/by-nc-nd/4.0/)
To overcome this drastic situation many of the scientists and researchers found different ways and opportunities by using locally available waste by-products from industries having pozzolanic properties like cement and partially or completely replacing them with cement content in concrete.

Another serious reason behind cement replacement is to reduce carbon dioxide emissions to the atmosphere to dissuade the global warming problem worldwideThe carbon emissions of the cement only during the manufacturing process is 1.5 billion tonnes which is $5-7 \%$ of the total $\mathrm{CO}_{2}$ emission globally in a year which is recorded as the highest contribution towards environmental pollution [13,14,17]. Hence low $\mathrm{CO}_{2}$ binding agents are abstracted from industrial by-products which are rich in silica and alumina such as Metakaolin[15,18], Fly ash[1,13,16,18], Ground Granulated Blast Furnace Slag (GGBFS)[1,15], Palm Oil Fuel Ash[26], calcinated clays, Rice Husk Ash (RHA) [31] and some natural zeolites. It is noted that the $\mathrm{CO}_{2}$ emission is reduced by $60 \%$ in the manufacturing of geopolymer concrete [15].

Metakaolin (MK) is proved to be better among all other binding agents and the Metakaolin geopolymer has persisting properties. But due to high water demand its properties are overpowered by some severe rheological errors [19]. Hence other materials are supposed to be considered by researchers. In recent years, the study for GC is highly appreciated at the international level which encourages scientists and researchers to expand their innovations. According to Zhang et al. (2018) [18] investigated for direct pull-out tests of 90 samples of GC cube casted with reinforcement bars of different diameters to know the change in bond characteristics of the samples in both ambient and elevated temperatures. The Flyash-based geopolymer concrete receives its best compressive strength in an elevated temperature curing as compared to ambient temperature curing [11]. It is also studied that the bond strength of GC decreases when the temperature exceeds $300^{\circ}$ C [18].

\section{MATERIALS AND METHODS}

\section{A. Materials}

Binder: As reviewed the industrial wastes are highly recommended by scientists and researchers as its harmful to the environment but excellent as a replacement to conventional cement having binding properties which also encourages a low carbon footprint. Most of the researchers used Fly ash as the major replacement of OPC for the manufacturing of geopolymer concrete $[5,11,12,13,16,29$, 30]. Some of them used the Fly ash and GGBS in different ratios in their GC mix to study various changes in mechanical properties [1, 2, 6, 14, 25]. 


\section{Geopolymer Concrete: an Emerging Green Material for Modern Construction}

Likewise, the investigation of only GGBS as binder replacing OPC is also done by many researchers [23, 26, 28].

However, J. Venkateswararao, K. Srinivasa Rao and K. Rambabu (2017) [4] used Fly ash, GGBS, and OPC in a confined ratio to study the performance of glass fiberreinforced GC. Paper sludge ash, Metakaolin, High Magnesium Nickel Slag (HMNS) can also be used for research investigation [9, 15, 18, 22, 24, 35].

Aggregates: Fine aggregates conforming IS standards are used for experimental purposes. The tests for the fine aggregates should be confirming to IS 2386 (Part III)-1963 [1]. The size of the fine aggregate particles should not exceed $2 \mathrm{~mm}$ [18]. For geopolymer concrete 10 - $20 \mathrm{~mm}$ size coarse aggregates are generally preferred [18]. In some cases, for an experimental purpose, other materials are also considered with a partial replacement of coarse aggregates such as hooked end steel fibers [1], recycled rubber pieces or Crumb [23], crushed granite [4], processed air-cooled Copper Slag [37].

Alkaline solution: Generally Sodium Hydroxide or Potassium Hydroxide pellets are dissolved in water to make a solution where the exothermic reaction takes place. After adding Sodium Hydroxide or Potassium Hydroxide the mixture is stirred for 2 minutes for complete dissolution of the solid pellets in water[13]. Then Sodium Silicate or Potassium Silicate solution is added to it in different ratios.

\begin{tabular}{|c|c|c|c|c|c|c|c|}
\hline Type of geopolymer & $\begin{array}{l}\text { Binder } \\
\text { used }\end{array}$ & Molarity & $\begin{array}{l}\mathrm{NaOH} / \\
\mathrm{Na} 2 \mathrm{SiO} 3 \text { ratio }\end{array}$ & $\begin{array}{l}\text { Binder } \\
\text { ratio }\end{array}$ & $\begin{array}{l}\text { Solution/ } \\
\text { Binder } \\
\text { ratio }\end{array}$ & $\begin{array}{l}\text { Water/ } \\
\text { binder } \\
\text { ratio }\end{array}$ & Additives \\
\hline $\begin{array}{l}\text { Srinivas et al.(2019) } \\
\text { [1] }\end{array}$ & $\begin{array}{l}\text { Fly ash- } \\
\text { GGBFS }\end{array}$ & $8 \mathrm{M}$ & 2.5 & 1.28 & 0.36 & 0.1 & $\begin{array}{l}\text { Conplast SP-430 } \\
\text { and hooked end } \\
\text { steel fibers }\end{array}$ \\
\hline Assiet al.(2016) [13] & Fly ash & $14 \mathrm{M}$ & 0.39 & - & - & 0.22 & $\begin{array}{ll}\text { Sika } & \text { Viscocrete } \\
2100 & \end{array}$ \\
\hline $\begin{array}{l}\text { Meng et al.(2019) } \\
{[15]}\end{array}$ & $\begin{array}{l}\text { GGBFS- } \\
\text { MK }\end{array}$ & - & - & 1.0 & - & 0.38 & - \\
\hline $\begin{array}{l}\text { Yacobet al.(2019) } \\
{[16]}\end{array}$ & $\begin{array}{l}\text { Class F fly } \\
\text { ash }\end{array}$ & $\begin{array}{l}8 \mathrm{M}, 14 \mathrm{M}, \\
16 \mathrm{M}\end{array}$ & 0.39 & - & 0.43 & 0.06 & $\begin{array}{l}\text { MasterGlenium- } \\
7500\end{array}$ \\
\hline $\begin{array}{l}\text { Venkateswararaoet } \\
\text { al.(2017) [4] }\end{array}$ & Fly ash & $12 \mathrm{M}$ & 2.5 & 0.87 & 0.4 & 0.1 & $\begin{array}{l}\text { Chopped strands of } \\
\text { glass fiber }\end{array}$ \\
\hline $\begin{array}{l}\text { Askarianet al.(2018) } \\
\text { [20] }\end{array}$ & $\begin{array}{l}\text { Fly ash- } \\
\text { GGBFS }\end{array}$ & - & 0.9 & 0.6 & 0.05 & 0.3 & - \\
\hline Aly et al.(2019) [23] & Slag & - & 0.38 & - & - & 0.07 & Rubber crumb \\
\hline
\end{tabular}

Alkaline solution activation: Alkaline solution for the geopolymer concrete is a very important task to be taken into account. It is generally made by using pellets of Sodium Hydroxide or Potassium Hydroxide with more than 99\% purity which are believed as strong alkalis [16]. The ratio of these alkalis is taken in molars. The review states that the molarities between $14 \mathrm{M}$ and $18 \mathrm{M}$ give the best strength results.

Yacobet al. (2019) [16] studied the shear strength of fly ash based geopolymer reinforced concrete beams by using 3
Fibers: Fibers are introduced in the geopolymer mixes in various forms by many researchers in order to study their physical and mechanical characteristics. The fibers used in the geopolymer are steel fibers, glass fibers, natural fibers, etc. The cotton fiber reinforced geopolymer concrete and achieved relatively higher compressive strength as a result [36].

Srinivas et al. (2019) [1] used low carbon hooked end steel fibers of $30 \mathrm{~mm}$ length and $0.6 \mathrm{~mm}$ diameter having a tensile strength of $1450 \mathrm{MPa}$. He observed that the compressive strength of 7 and 28 days for samples with constant molarity of alkaline solution increases with increase in volume fraction of steel fibers.

The inclusion of glass fibers in geopolymer concrete causes a reduction in slump value in fresh state and the compressive strength for a change decreases with an increase in volume ratio of glass fibers. Whereas the splitting tensile strength and flexural strength shows a hike [4]. In some cases, rubberized geopolymer concrete is examined.

Aly et al.(2019) [23] used crumb rubber collected from automotive and truck scrap tires of specific gravity 0.45 to investigate its performance by using slag as a binder. He observed that the slump value decreases but the compressive strength is slightly increased to $10 \%$. The compressive strength also increases by using large sized aggregates and $\mathrm{NaOH}$ or $\mathrm{Na}_{2} \mathrm{SiO}_{3}[29]$. different $\mathrm{NaOH}$ molarity 8M, 14M, 16M. Cao et al.(2018) [21] used 10M, 12M, 14M. Sodium silicate or K2SiO3 is used in either dissolving solid crystals in water or directly in prepared solution with the alkaline solution to complete the reaction. 
It should be taken into account that the $\mathrm{NaOH}$ or $\mathrm{KOH}$ when mixed with water it should be stirred for complete dissolution and during this, the solution goes under exothermic reactions. After the solution is prepared it should be kept in a hot oven for 12 hrs. at a temperature of $75^{\circ} \mathrm{C}$ and then at room temperature for 24 hrs to cool down [13]. It should be noted that the solution is required to be prepared before $24 \mathrm{hrs}$ from the time of its use for the best results [31]. As the alkaline solution is exothermic in nature its proper precautions and safety should be maintained.

\section{B. Mix Design And Curing}

First of all the dry ingredients are being mixed together to form a homogenous texture including fine and coarse aggregates.

After mixing the prepared alkaline solution of the required molarities is added to it by continuously mixing them together. The addition of extra water is applicable in case of requirement. In some of the cases, admixtures are added to it to improve its workability and strength factor $[1,13,16,18$, $25,26,27]$. Many researchers and some others utilized some extra fibres like rubber crumb, hooked end steel fibres, glass fibres, etc to the concrete to study the various changes in their structural and mechanical behaviour and durability factors [1, 4, 23].

After the concrete is properly mixed it was kept in cubes of $100 \mathrm{~mm} \times 100 \mathrm{~mm} \times 100 \mathrm{~mm}$ or $150 \mathrm{~mm} \times 150 \mathrm{~mm} \times 150 \mathrm{~mm}$, cylinders, beams, columns or slabs and left for minimum 24 hrs. to set properly without any disturbance with required compactions. After $24 \mathrm{hr}$. the concrete members are demoulded and either kept in a pre-heated oven for hot air curing or in an open environment for moderate temperature curing [31].

\section{Effects Of Alkali Activator Ratio (AAR), W/B Ratio And AAR/Binder Ratio On Geopolymer Concrete}

The AAR has a great impact on the compressive strength of the geopolymer concrete [32]. The $\mathrm{NaOH}$ is a key for increasing the workability of the concrete but gets dominated by sodium silicate which reduces it and the increase in $\mathrm{NaOH} / \mathrm{Na} 2 \mathrm{SiO} 3$ ratio reduces the workability and promotes the compressive strength of the geopolymer concrete [22]. The mechanical properties enhance with increasing AAR [22]. It is necessary to choose a suitable AAR to achieve a proper setting time as well as compressive strength [21]. The higher w/b ratio indicates a reduction in compressive strength drastically. When the ratio of AAR to the binder was kept steady at $7.5 \%$ a decrease in slump value is observed [20].

\section{Microstructure}

The microstructures of the materials highly influence factors like strength, toughness, ductility, hardness, temperature effects and wear resistance. Bharadwaj and Kumar [28] studied the microstructure of Fly ash and GGBS by using scanning electron microscopy (SEM) imaging on Quanta FEG 450 of 28 days cured concrete samples.

Noushiniet al. (2018) [38] has done micro-structural analysis of fly ash using a Hitachi S-3400 N SEM where the samples are cold mounted in an epoxy resin and were polished with a finer sandpaper after which the samples are coated with carbon.
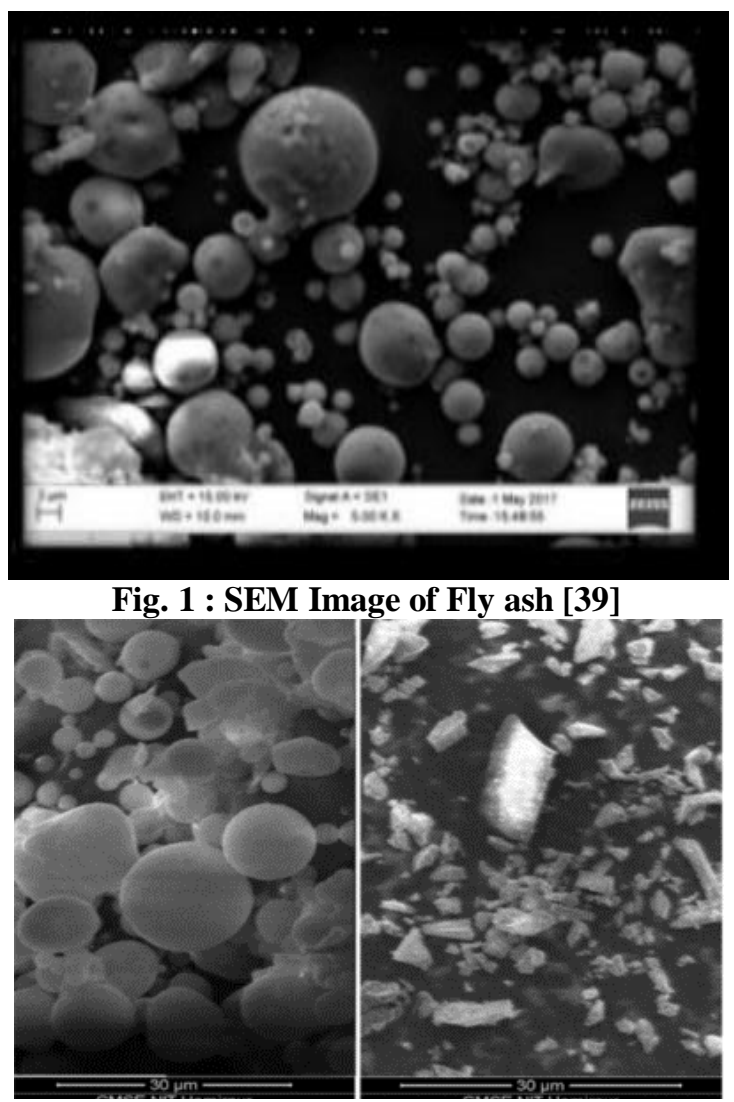

Fig. 2. SEM Images of Fly ash (Left) and GGBS (Right) [28]

\section{RESULTS AND DISCUSSIONS}

\section{A. Fresh State Tests}

Slump test:Slump test is required to identify the workability of the concrete in its fresh state and if needed some amount of extra water is added to it. In the slump test, the measurement of the flow dimensions in both $\mathrm{X}$ and $\mathrm{Y}$ directions and the time at which the diameter of flow reaches $500 \mathrm{~mm}$ are recorded. The geopolymer concrete achieves the highest workability during the slump test which is $122 \mathrm{~mm}$ $145 \mathrm{~mm}[16,20,21,24]$.

\section{B. Tests after curing}

Compressive Strength Test: Zhang et al.(2019) [18] studied the effects of temperature on the bond characteristics of the geopolymer concrete in the year 2018. After the demonstration, he got to know that the compressive strength varies irregularly till the temperature reaches $300^{\circ} \mathrm{C}$. After which it starts to reduce continuously.

The compressive strength of a one-part hybrid geopolymer concrete sample at 3,7 and 28 days respectively in a universal testing machine at a loading rate of $20 \pm 2$ $\mathrm{MPa} / \mathrm{min}$ according to AS1012.9 [20]. It is identified that the compressive strength was low in ordinary OPC cubes whereas higher in the case of hybrid geopolymer concrete cubes. The compressive strength of alkali-activated slag GC mix is better than any other GC mixes at different variations [28]. 


\section{Geopolymer Concrete: an Emerging Green Material for Modern Construction}

Splitting Tensile Strength: According to S. Jena and R. Panigrahi(2019) [31] the splitting tensile for a geopolymer concrete specimen with $14 \mathrm{M}$ is excellent and it increases with increase in $\mathrm{NaOH}$ concentration between $8 \mathrm{M}$ to $14 \mathrm{M}$. But the strength reduces from $14 \mathrm{M}$ to $18 \mathrm{M}$.

The STS test for a Class F Fly ash geopolymer specimen with reference to IS : 5816-1999 at 28, 90 and 365 days where it ranges from 5.34-5.49 MPa [30].

Flexural Strength Test: Flexural strength test also referred as 3 -point load test is investigated by many of the researchers. Aly et al. (2019) [23] examined the flexural strength of OPC replaced by GGBS in different ratios and concluded that the flexural strength for the control mix design is greater than any other mix design geopolymer concrete containing recycled rubber cuts.

Luharet al. (2019) [30] studied for the strength and durability factors of the rubberized geopolymer concrete in which he concluded the flexural strength varies from 6.459.97 MPa.

He said that flexural strength for the geopolymer concrete is higher as compared to the usual OPC concrete and it increases with age in all mix designs.

\section{Durability}

The durability of the geopolymer concrete is investigated by many researchers in different ways. The resistance of geopolymer concrete samples to the chloride diffusion was studied by using ASTM C1556 [28] which states that the low calcium Fly ash based geopolymer concretes are less resistant to chloride attacks. Continuous freeze-thaw cycles lead to a loss in weight of the geopolymer specimens surface exfoliation and water absorption properties of it. It also reduces the compressive strength of the sample [35].

The geopolymer concretes are more resistant to sulphate attack than OPC concrete when exposed to normal exposure conditions. But strength loss was observed at an age of 28 day [32].

\section{CONCLUSION}

This paper appraised the study of geopolymer concrete in terms of structural ability and effect on the mechanical and physical properties of the GC. In this study, the comparison among the ordinary OPC concrete and that is based on alumina-silicate sources that are received from various industrial wastes were investigated. Among all other, Class F Fly ash was wide used source of alumina silicate and in some cases as a replacement to the OPC in a certain percentage. Some of the findings can be expressed as the following:

a) The GC as compared to the OPC is found to be more efficient. They attain the compressive strength much higher than OPC.

b) The rubberized geopolymer concrete loses its strength with gain in quantity of rubber crumb and the strength also decreases when the samples are exposed to an elevated temperature above $600^{\circ}$ C. Reduction in flexural strength is observed with increase in waterbinder ratio.

c) The GC receives greater compressive strength in elevated temperatures than that of moderate or ambient temperatures. d) All other factors except poison's ratio decrease with an increase in water-binder ratio.

e) The bond strength in GC is higher than that of OPC due to good binding capacity among the binder and aggregates.

f) Cracks formed in geopolymer concrete are minor and less as compared to OPC.

g) The use of Nano Silica slightly reduces the compressive strength. Whereas the mixing of glass or steel fibers increases the same.

\section{REFERENCES}

1. Sreenivas, J. Srinivas1 B. Sesha, and D. Rama Seshu. "An Experimental Study on Compressive Strength of Steel Fibre Reinforced Geopolymer Concrete (SFRGPC) with Different GGBS \& Fly Ash Proportions." (2018).

2. Jayakumar, Karthikeyan. "Effect of GGBS and Fly ash aggregates on properties of geopolymer concrete." Journal of Structural EnginEEring 43.5 (2016).

3. Pazhani, K. C., and K. Ravisankar. "Studies on fly ash and slag blended geopolymer concrete." (2017).

4. J. Venkateswararao, K. Srinivasa Rao and K. Rambabu. 2017. Performance of glass fibre reinforced geopolymer concrete composites. J. of Structural Eng. 44(2):184-190.

5. S. Mani and B. Pradhan. 2017. A study on compressive strength and corrosion behaviour of reinforcing steel in chloride contaminated fly ash based geopolymer concrete. J. of Structural Eng. 44(3):214-219.

6. S. Khan, D. Brindha and K.L. Muthuramu. 2017. An experimental investigation of fly ash-GGBS based high strength geopolymer concrete incorporating copper slag. J. of Structural Eng. 44(4):364376.

7. N. Anuja and S.Prabavathy. 2018. Study on geopolymer mortar using hydrogen peroxide as foaming agent. J. of Structural Eng. 45(2):139147.

8. S. Khan, D. Brindha and G.Panneerselvam. 2018. Mechanical behaviour of pre-stressed railway sleepers using geopolymer concrete. J. of Structural Eng. 45(2):187-200.

9. P. Senthamilselvi and T. Palanisamy. 2018. Flexural behaviour of reinforced fly ash and paper sludge ash-based geopolymer concrete beams. J. of structural Eng. 45(2):201-209.

10. H. Zhang, M.N.S. Hadi. 2019. Geogrid-confined pervious geopolymer concrete piles with FRP-PVC confined concrete core: Concept and behaviour. Construction and Building Materials. 211:12-25.

11. G. Saravanan and C. A. Jeyasehar. 2018. A study of durability parameters on fly ash based geopolymer concrete using electrical analyser. J. of structural Eng. 45(4):359-366.

12. K. Ramujee. 2018. Engineering properties of fly ash based geopolymer concrete. J. of structural Eng. 45(4):385-394.

13. L.N. Assi, et al. 2016. Investigation of early compressive strength of fly ash-based geopolymer concrete. Construction and Building Materials. 112:807-815.

14. D.A. Salas, et al. 2018. Life cycle assessment of geopolymer concrete. Construction and Building Materials. 190:170-177.

15. Q. Meng., et al.2019. Experimental and numerical investigation of blast resistant capacity of high performance geopolymer concrete panels. Composites Part B.171:9-19.

16. N.S. Yacob,et al. 2019. Shear strength of fly ash-based geopolymer reinforced concrete beams. Eng. Structures. 196:109-298.

17. P. Visintin, et al. 2017. Shear behaviour of geopolymer concrete beams without stirrups. Construction and Building Materials. 148:10-21.

18. H.Y. Zhang,et al.. 2018. Effect of temperature on bond characteristics of geopolymer concrete. Construction and Building Materials. 163:277-285.

19. C.K. Ma, A.Z. Awang and W. Omar. 2018. Structural and material performance of geopolymer concrete: A review. Construction and Building Materials. 186:90-102.

20. M.Askarian, et al. 2018. Mechanical properties of ambient cured one-part hybrid OPC-geopolymer concrete. Construction and Building Materials. 186:330-337.

21. Yi-Fang Caoet al.2018. Effect of calcium aluminate cement on geopolymer concrete cured at ambient temperature. 
22. Construction and Building Materials. 191:242-252.

23. M.Koushkbaghi, et al. Influence of different monomer ratios and recycled concrete aggregate on mechanical properties and durability of geopolymer concretes. Construction and Building Materials. 205:519-528.

24. A.M. Aly, et al. 2019. Performance of geopolymer concrete containing recycled rubber. Construction and Building Materials. 207:136-144.

25. A. Bouaissi,et al.2019. Mechanical properties and microstructure analysis of FA-GGBS-HMNS based geopolymer concrete. Construction and Building Materials. 210:198-209.

26. M.E.Gülsan, et al. Development of fly ash/slag based selfcompacting geopolymer concrete using nano-silica and steel fibre. Construction and Building Materials. 211:271-283.

27. Saranya P, P. Nagarajan and A.P. Shashikala. 2019. Performance evaluation of geopolymer concrete beams under monotonic loading. Structures. 20:560-569.

28. M. Dong, et al.2019. Modelling glass fibre-reinforced polymer reinforced geopolymer concrete columns. Structures. 20:813-821.

29. B. Bhardwaj and P. Kumar. 2019. Comparative study of geopolymer and alkali activated slag concrete comprising waste foundry sand. Construction and Building Materials. 209:555-565.

30. Y. Park,et al.2016. Compressive strength of fly ash-based geopolymer concrete with crumb rubber partially replacing sand. Construction and Building Materials. 118:43-51.

31. S.Luhar, S. Chaudhary and I.Luhar. 2019. Development of rubberized geopolymer concrete: Strength and durability studies. Construction and Building Materials. 204:740-753.

32. S. Jena and R. Panigrahi. 2018. Parametric study on sustainable geopolymer concrete. Int. J. Sustainable Materials and Structural Systems. (2018).

33. A.B. Malkawi, et al. 2016. Effects of Alkaline Solution on Properties of the HCFA Geopolymer Mortars. Sci. Direct. 148:710- 717.

34. M. Askarian, et al. 2018. Mechanical properties of ambient cured one-part hybrid OPC-geopolymer concrete. Construction and Building Materials. 186:330-337.

35. K.H. Mo, U.J. Alengaram and Mohd Z. Jumaat. 2016. Structural performance of reinforced geopolymer concrete members: A review. Construction and Building Materials. 120:251-264.

36. E. Adesanya,et al.2018. One-part geopolymer cement from slag and pre-treated paper sludge. J. of Cleaner Production. 185:168-175.

37. T. Alomayri, F.U.A. Shaikh and I.M. Low. 2013. Characterisation of cotton fibre-reinforced geopolymer composites. Composites: Part B. 50:1-6.

38. M. Criado, S.A. Bernal. 2017. Sustainable and Nonconventional Construction Materials using Inorganic Bonded Fibre Composites. Woodhead publishing.

39. A. Noushini, et al. 2018. Mechanical and flexural performance of synthetic fibre reinforced geopolymer concrete. Construction and Building Materials. 186:454-475.

40. M.V. Raut and S.V. Deo. 2019. Influence of high volume Fly ash as a replacement of cement and sand along with a glass fibre on the durability of concrete. Int. J. of Eng. and Advance Tech. 8(5):42-48.

\section{AUTHOR'S PROFILE}

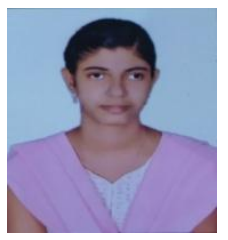

Ritupanna Panda is a research scholar pursuing $\mathrm{M}$. Tech in Structural Engineering at Centurion University of Technology and Management, Bhubaneswar. She is graduated. from Centurion University of Technology and Management, Bhubaneswar in Civil Engineering stream. She is currently doing research work on various aspects of "Geopolymer Concrete" on construction industry.

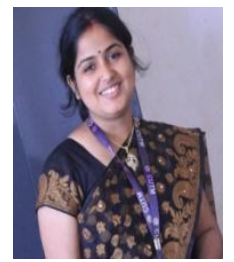

Prof. Sagarika Panda has obtained her M. Tech in Structural Engineering from College of Engineering and Technology, Bhubaneswar in 2012.She is graduated. from Orissa Engineering College, Bhubaneswar in Civil Engineering in 2010. She is basically working on green and sustainable building materials, high-strength concrete and solid waste management. She has been in the teaching profession for the last seven years. She has published papers in national and international journals and conferences. She is currently working as an assistant professor in the Department of Civil Engineering, Centurion University of Technology and Management, Bhubaneswar.

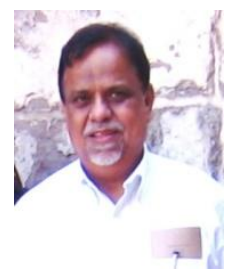

Dr.ArdhenduMouli Mohanty graduated in Mechanical Engineering from UCE, BURLA in the year 1973. He obtained M. Tech in Production Science \& Technology from IIT Kharagpur and PhD in Welding Engineering from IIT Madras. Joined BHEL as an Engineering Trainee and worked in BHEL for 18 years. He was a shop floor engineer and worked in pressure vessel fabrication, quality assurance for boilers and also in erection sites. He worked at Paradeep Phosphates Ltd as Head of Projects specialized in renovation and capacity expansion projects of fertilizer plants. Presently Pro Vice Chancellor at Centurion University engaged in research, teaching and academic administration. The main area of research is Welding and Electro Discharge Machining. 